Article

\title{
Measurements of Optical Properties of Smoke Particulates Produced from Burning Polymers and Their Implications
}

\author{
Ter-Ki Hong ${ }^{1}$, Beom-Seok Roh $^{2}$ and Seul-Hyun Park ${ }^{3, *}$ \\ 1 Department of Mechanical System \& Automotive Engineering, Graduate School of Chosun University, \\ Chosun University, Gwangju 61452, Korea; catzeyeh@gmail.com \\ 2 Education \& Operation Team, Korea Institute of Maritime and Fisheries Technology, Busan 49111, Korea; \\ bsro@seaman.or.kr \\ 3 School of Mechanical System \& Automotive Engineering, Chosun University, Gwangju 61452, Korea \\ * Correspondence: isaac@chosun.ac.kr; Tel.: +82-62-230-7174; Fax: +82-62-230-7171
}

Received: 13 March 2020; Accepted: 28 April 2020; Published: 7 May 2020

check for updates

\begin{abstract}
A series of cone calorimetry experiments and simultaneous gravimetric sampling and light extinction (GSLE) measurements were performed to determine the optical properties (light obscuration and extinction characteristics) of smoke particulates produced from burning polymers. The polymer selected in the present study was acrylonitrile-butadiene styrene (ABS), which has a moderate smoke yield during combustion, and unplasticized polyvinyl chloride (UPVC), which has a lower smoke yield than ABS. The experiments show that the measured light obscuration for UPVC smoke particles is much lower than that for ABS smoke particles because of the low rate of smoke production during combustion. Results from the simultaneous GSLE measurements demonstrate more clearly that UPVC smoke particles represent a lower efficiency of light obscuration on a per-unit smoke mass basis, resulting in a $41.3 \%$ reduction in a mass specific extinction coefficient compared to the ABS smoke particles. Numerical analysis was performed to further elucidate the effect of optical properties on the smoke behavior using the Fire Dynamics Simulator (FDS) (Version 6.7.1, National Institute of Standards and Technology (NIST), Gaithersburg, MD, USA). The numerical results clearly demonstrated that the UPVC combustion, with its relatively low heat release rate and mass specific extinction coefficient, caused a significant delay in detecting a fire with a smoke detector compared to ABS combustion.
\end{abstract}

Keywords: light obscuration; mass specific extinction coefficient; polymer; smoke; fire

\section{Introduction}

Radiative heat transfer plays an important role in fire growth and spread, providing almost all the energy transferred to combustibles. In particular, the presence of smoke particulates allows up to $50 \%$ of the energy in pool fires to radiate back to the pool of fuel [1]. Knowledge of the optical properties of smoke particulates-known as dimensionless light extinction constant, $K_{e}$-is critical to the development of one of the key parameters, the Planck mean absorption coefficient, $K_{P}$, for use in thermal radiation analysis for smoke particulates [2]:

$$
K_{P}=3.83 f_{v} K_{e} T / C_{2}
$$

where $f_{v}$ is the smoke volume fraction, $T$ the temperature, and $C_{2}$ Planck's second constant. As important as they are in thermal radiation analysis, the optical properties of smoke particulates are also essential to measure the smoke volume fraction accurately. 
It has been reported that more than $80 \%$ of fire deaths are related to smoke particulates generated by combustion $[3,4]$. In particular, hot and toxic smoke inhalation is considered a fatal effect that leads to the death of fire victims. Therefore, smoke suppression is a key problem in the mitigation of potential fire hazards. To access and evaluate the suppression of smoke produced from fires, the smoke volume fraction must be measured accurately. The most conventional method for measuring the smoke volume fraction in the fire science community is a non-intrusive optical measurement that requires an in depth understanding of the light extinction characteristics of smoke particulates. Moreover, the presence of smoke in fires reduces the visibility because of light absorption and scattering by particulates (that also strongly depend on their optical properties, specifically light extinction characteristics); this lowers the possibility of finding exit signs and doors during emergency evacuation.

The light extinction characteristics of smoke particulates can be predicted from an appropriate model combined with the knowledge of the refractive index of particulates. However, this has proven to be complicated owing to very large uncertainties in the refractive index of particulates [5-7]. Moreover, Flame generated particulates agglomerate into wispy chains that consist of hundreds of nanometers to several micrometers in length [8]. Particularly, smoke particulates are usually porous aggregates, which can be interpreted as a mixing of carbon elements with air cavities $[9,10]$. Such heterogeneous substances, whose morphology and chemical compositions vary in which they have formed and grown [1], can greatly influence their optical properties [9,10], and thus, make it difficult to accurately predict the light extinction characteristics using the optical model such as the Mie or Rayleigh-Debye-Gans (RDG) theory. For example, Choi et al. [11] performed gravimetric sampling as an independent measurement of the volume fraction of flame generated particulates to alternatively calculate the dimensionless extinction coefficient with the light extinction technique. The measured dimensionless extinction coefficient was a factor of two greater than the value of 4.9 calculated using Mie theory with the refractive index of $\mathrm{m}=1.57-0.56 \mathrm{i}[12,13]$.

Polymers have been increasingly used as construction materials in home and building applications. In case of fire, polymers as solid fuel undergo thermal decomposition, emitting toxic gases as well as smoke particulates [14-16]. In particular, acrylonitrile-butadiene styrene (ABS), with a low thermal stability, produces numerous aromatic compounds in thermal decomposition, which favorably results in the formation of carbon nucleuses, leading to potential smoke yields [17]. Unplasticized polyvinyl chloride (UPVC), which is another important technical polymer, has a lower flammability. The presence of chlorine in UPVC causes the splitting off of hydrogen chloride (HCI) species at high temperatures $[18,19]$. HCIs formed after the onset of thermal decomposition are found to increase char formation, resulting in a reduction in the flammable decomposition products [19]. Therefore, UPVC produces less heat in combustion compared to other polymeric materials and is self extinguishing when the heat source is removed. However, it is important to note that UPVC exposed to a real fire is forced to burn continuously and produces significant smoke yields [19].

Smoke suppression of polymeric materials is one of key problems in mitigating potential fire hazards. To access and evaluate the suppression of smoke produced from burning polymeric materials, smoke yields must be measured accurately. The most conventional method for evaluating smoke yield in the fire science community is non-intrusive optical measurement, which requires an in depth understanding of the optical characteristics of smoke particles. However, limited investigations have qualitatively assessed the optical characteristics of smoke produced from burning polymeric materials. The objective of the present study is to provide such optical characteristics for smoke-emitting polymers ABS and UPVC, and to qualitatively evaluate their attendant impacts on fire evacuation. To this end, light obscuration analysis based on simultaneous gravimetric sampling and light extinction (GSLE) measurements and computational simulations of smoke behaviors were performed.

\section{Materials and Methods}

A series of burning experiments of smoke-emitting polymers, ABS and UPVC, were carried out using a cone calorimeter (as shown in Figure 1) in accordance with the International Organization for 
Standardization (ISO) 5660-1. The cone calorimeter is an apparatus commonly used for quantifying the fire behavior of materials [20,21]. An external radiant heat flux of $50 \mathrm{~kW} / \mathrm{m}^{2}$ from a conical heater was applied to the ABS and UPVC samples. The ABS and UPVC samples were cut to 100 (W) $\times 100(\mathrm{~L}) \times$ 10 (T) $\mathrm{mm}$ and fixed to the sample holder. The mass of ABS and UPVC samples measured before the start of the experiment was $123 \mathrm{~g}$ and $146 \mathrm{~g}$, respectively. A metal mesh on the sample holder was placed and secured to prevent ABS and UPVC samples from swelling out of the holder during the burning experiments. The electric sparks generated from a pilot ignitor ignited combustible gases emitted from the heated polymeric materials, eventually creating a flame. After ignition, the smoke-containing flow (24 slpm) was directed to the exhaust duct of the cone calorimeter. The cone calorimeter used in this study was equipped with a stainless steel smoke sample tube with a $6.3 \mathrm{~mm}$ outer diameter on the exhaust duct. The sampling line was directly connected to the transmission cell (TC) for simultaneous gravimetric sampling and light extinction (GSLE) measurements through a dilution chamber that is designed to ensure good mixing conditions. The sampling flow was controlled to keep a constant smoke-containing flow to the dilution chamber which is typically set to $1 / 200$ of the exhaust duct flow [22]. Thermophoretic deposition of smoke particles in the sampling line due to rapid cooling of air flow was minimized by heating the sampling line.
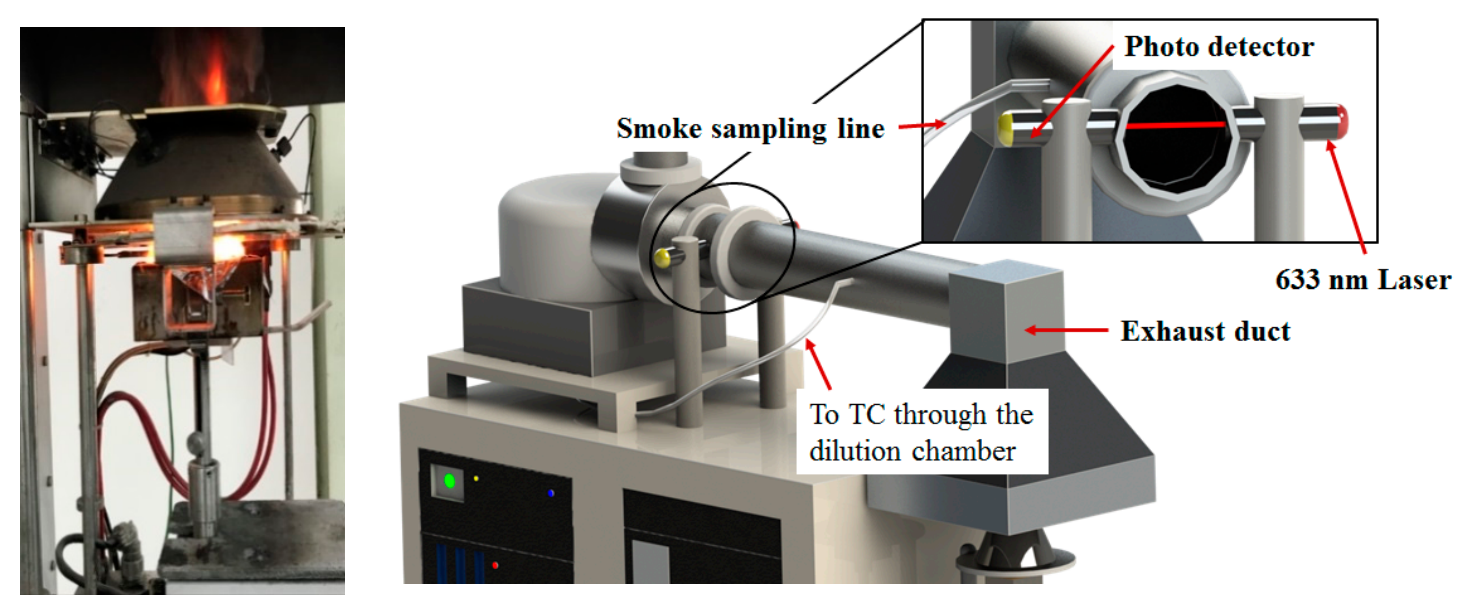

Figure 1. Burning experiments of acrylonitrile-butadiene styrene (ABS) and unplasticized polyvinyl chloride (UPVC) with ISO 5660-1 cone calorimeter. TC: transmission cell.

To qualitatively analyze the characteristics of light obscuration caused by ABS and UPVC smoke particulates, the mass specific extinction coefficient, $K_{m}$, was measured using a simultaneous gravimetric sampling and light extinction (GSLE) technique $[23,24]$. In this technique, the smoke volume fraction is gravimetrically measured and then compared to that measured optically using the Beer-Lambert Law. Further details on this technique and experimental apparatus can be found elsewhere [11,25].

The experimental set-up for the simultaneous GSLE measurement is shown in Figure 2. The smoke particles from burning ABS and UPVC in the cone calorimeter are delivered to the TC through the dilution chamber. The additional airflow into the dilution chamber was varied to adjust the smoke containing flow to the TC. A vacuum pump was used to create the smoke containing flow to the TC. A mass flow controller attached downstream of the TC was used to maintain a constant smoke-containing flow during the GSLE measurements. A TC equipped with optical windows (with anti-reflection coating) at both the inlet and outlet ports provided a laser path length $(L)$ of $0.8 \mathrm{~m}$. 
GSLE (Gravimetric Sampling and Light Extinction)

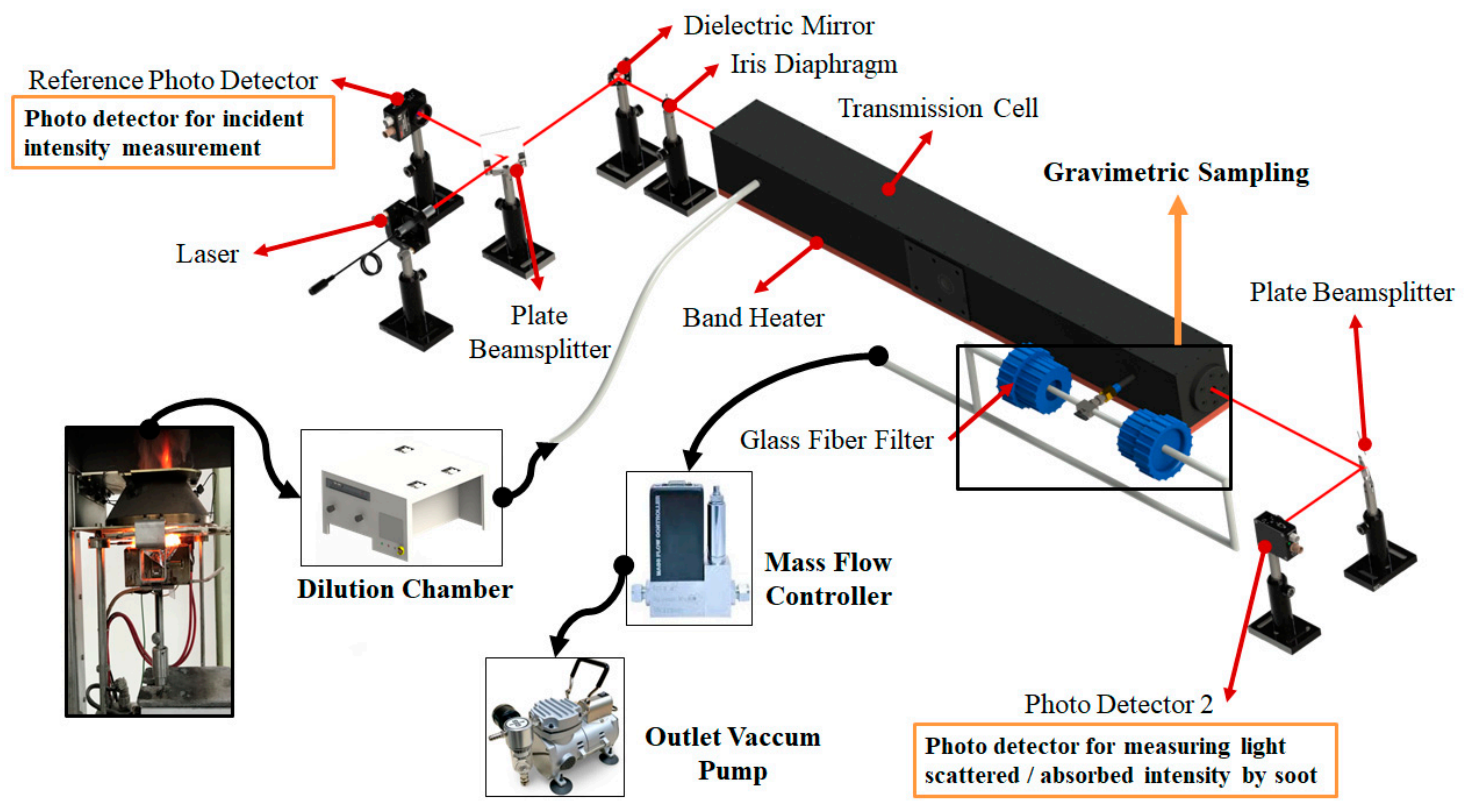

Figure 2. Schematics of experimental set-up for simultaneous gravimetric sampling and light extinction (GSLE) measurement.

In the GSLE measurements, a $5 \mathrm{~mW}$ helium-neon diode laser of wavelength $635 \mathrm{~nm}$ was used as the light source. The laser beam was directed through the TC using mirrors and beam splitters to a silicon photodiode detector with an operating range of $400 \mathrm{~nm}$ to $1100 \mathrm{~nm}$. Two silicon photodetectors used in this study were equipped with a bandpass filter $(635 \mathrm{~nm}$ with a full width at half maximum (FWHM) of $10 \mathrm{~nm}$ ). The light obscuration per unit length due to smoke particles, $C_{s}$ (commonly referred to as the smoke optical density) in the TC was calculated based on Beer-Lambert Law [26]:

$$
C_{s}=-\frac{1}{L} \ln \left(\frac{I}{I_{0}}\right)=\frac{K_{e} f_{v}}{\lambda}
$$

where $L$ is the laser path length, $I_{0}$ the incident laser intensity measured prior to the introduction of the smoke-containing flow into the duct, $I$ the transmitted-laser intensity, $K_{e}$ dimensionless light extinction coefficient, $f_{v}$ smoke volume concentration, and $\lambda$ the wave length of light source. The fundamental assumption of Beer-Lambert Law remains in stability of laser in terms of intensity during the measurement period. To ensure the stability of incident-laser intensity in real time, another beam splitter was implemented on the laser pathway and diverted a fraction of beam to the reference photodiode detector as shown in the figure.

The smoke containing flow was directed to one of the filter assemblies containing a glass-fiber filter that has a collection efficiency greater than $99 \%$ for particles larger than $0.1 \mu \mathrm{m}$ in size. After the GSLE measurements were taken, the mass of smoke particles sampled on the glass-fiber filter was weighed using a microbalance. The gravimetrically determined smoke volume fraction, $f_{v g}$, was then calculated using the following relationship:

$$
f_{v g}=\frac{m_{s}}{V t \rho_{s}}
$$

where $m_{S}$ is the measured mass of smoke particles collected on the filter, $V$ the volumetric flow rate of the smoke containing flow, $t$ the particle sampling time, and $\rho_{s}$ the density of the smoke particles.

The degree of smoke particles deposition in the TC will create discrepancies between the smoke volume fraction based on light extinction and gravimetric sampling techniques and will violate the 
condition that the smoke volume fraction measured using gravimetric technique, $f_{v g}$, is equal to the smoke volume fraction measured using the light extinction method, $f_{v}$. In the present study, the entire TC, including two optical ports, was heated using a band heater and maintained at approximately $50{ }^{\circ} \mathrm{C}$ to prevent smoke particles deposition during the measurement period. The thermophoretic force caused by the presence of the heated TC repels approaching smoke particles, making them suspended inside the TC. It was found that the thermophoretic force generated under the given smoke containing flow of $7 \mathrm{slpm}$ successfully remove smoke particle deposition in the TC before particles reaching the outlet.

\section{Results and Discussions}

Figure 3 displays the measured heat release rate from the cone calorimetry experiments as function of time. As displayed in the figures, the measured heat release rate for both UPVC and ABS samples increased after ignition, reached a quasi-steady condition, and began to decrease as flame extinction occurred. The pyrolysis of UPVC and ABS samples was found to lead to formation of char, which can insulate the underlying layer from an incident heat flux so that the net heat flux at the in depth pyrolysis front decreases with time [17]. As a result, the measured heat release rate for both polymer samples drastically decreased with time. However, the measurements clearly exhibit distinct heat release peaks between UPVC and ABS samples. A significant decrease in the peak heat release for UPVC, relative to ABS was observed. UPVC is an inherently flame-retardant polymer since it contains a higher chlorine content, which suppresses the release of heat from the flame [8,12]. A significant decrease in heat release for UPVC can result in a decrease in smoke production rate, lowering the $C_{S}$ values.

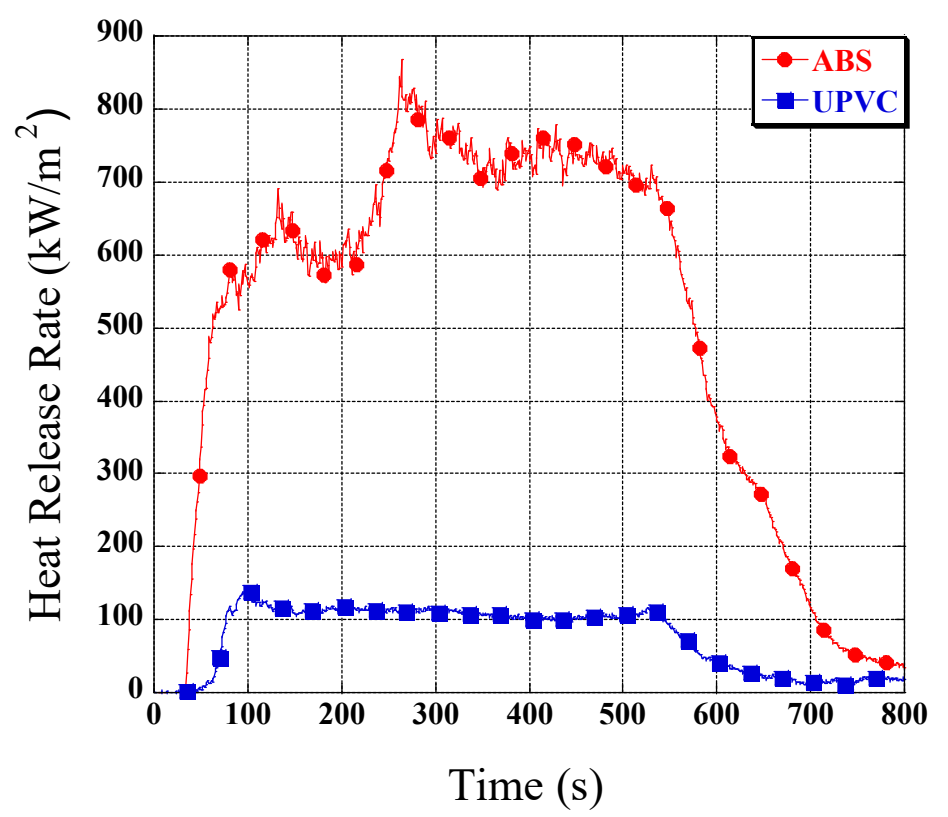

Figure 3. Heat release rate (HRR) measured as a function of time.

In the present study, GSLE experiments that enable the measurement of light obscuration on a per-unit smoke-concentration basis were performed. A typical light attenuation in the TC of the GSLE apparatus is shown in Figure 4. As soon as a constant smoke-containing flow (7 slpm) was drawn into the TC, the transmitted-laser intensity $(I)$ began to decrease as a result of light absorption and scattering by smoke particles, while the incident-laser intensity $\left(I_{0}\right)$ (monitored using a reference photodetector) was kept constant. As a result, the incident light began to be attenuated with the smoke filling the TC, eventually resulting in light obscuration. The average value of light attenuation $\left(I / I_{0}\right)$ was acquired from a quasi-steady sampling period of smoke particles for approximately $200 \mathrm{~s}$. 


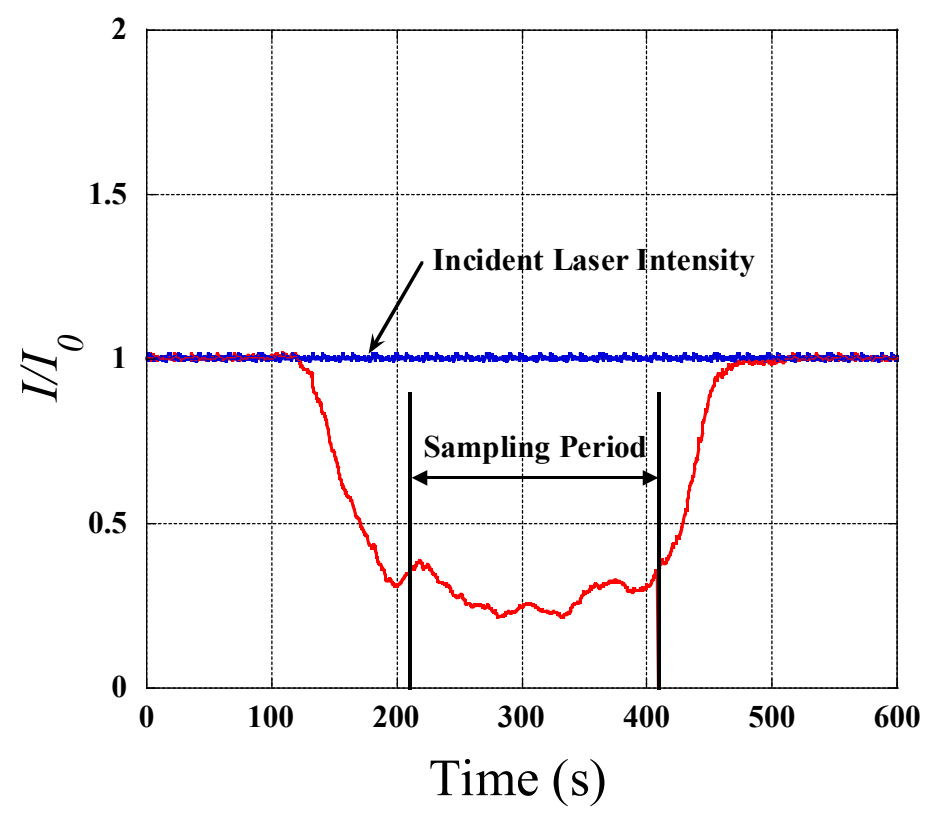

Figure 4. Light attenuation in TC measured as a function time.

The smoke volume fraction (determined using Equation (2)) plotted against the corresponding $C_{S}$ values are displayed in Figure 5. In the figure, the smoke loading into the TC was adjusted to produce a wide range of light obscuration represented by $C_{s}$. The linearity established between the smoke loading and the $C_{s}$ value confirms the foundation for simultaneous GSLE measurements [16]. Light obscuration behaviors per unit smoke concentration for each polymeric material are clearly observed in Figure 5. As displayed, the light obscuration for UPVC smoke particles is always smaller than that for the ABS smoke particles at the same volume fraction, $f_{v g}$.

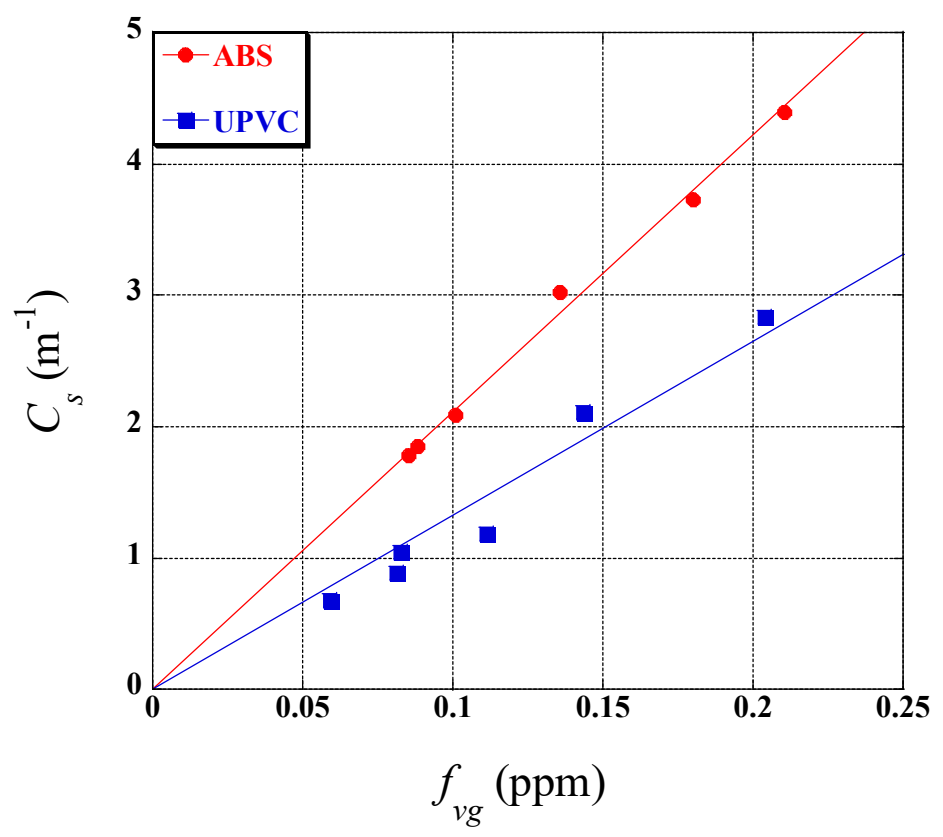

Figure 5. Light obscuration plotted as a function of smoke volume fraction.

The difference in light obscuration behaviors measured on a per unit volume fraction basis can be attributed to the density and light extinction characteristics of the smoke particles. In the GSLE technique, the smoke density must be accurately known to evaluate the dimensionless light extinction 
coefficient, $K_{e}$, as the value used in the calculation can lead to the uncertainties in $K_{e}$. The typical value of soot density $\left(\rho_{s}\right)$ for different fuels varies from $1.74 \mathrm{~g} / \mathrm{cm}^{3}$ to $2.05 \mathrm{~g} / \mathrm{cm}^{3}$. Since the density of ABS and UPVC smoke particles is not documented in the literature, the most used density of smoke particles used in the GSLE experiments, namely $1.74 \mathrm{~g} / \mathrm{cm}^{3}$ [25], was used for the calculation of $f_{v}$. In the present study, the influence of the smoke density can be removed by calculating instead the value of the mass specific extinction coefficient, $K_{m}$, using the following Equation:

$$
K_{m}=\frac{K_{e}}{\rho_{s} \lambda}=\frac{C_{s}}{f_{v} \rho_{s}}
$$

Because $f_{v}$ must be equal to $f_{v g}$ in the GSLE measurements, Equation (5) can be rewritten to evaluate the $K_{m}$ :

$$
K_{m}=\frac{C_{s} V t}{m_{s}}=-\frac{V t\left(\ln \frac{I}{I_{0}}\right)}{L m_{s}}
$$

The estimated combined Type B uncertainty in the mass specific extinction measurement was evaluated using Equation (6) and the parameters contributing to the Type B uncertainty are summarized in Table 1.

$$
\frac{\delta K_{m}}{K_{m}}=\sqrt{\sum_{n}\left[\frac{S_{n}}{K_{m}} \times \frac{\partial K_{m}}{\partial S_{n}} \times \frac{\delta S_{n}}{S_{n}}\right]^{2}}
$$

Table 1. Summary of Type B uncertainties in the mass specific extinction measurement.

\begin{tabular}{cccc}
\hline Source, $S$ & $\frac{\partial K_{m}}{\partial S_{n}}$ & $\frac{S_{n}}{K_{m}} \cdot \frac{\partial K_{m}}{\partial S_{n}}$ & $\frac{\delta S_{n}}{S_{n}}$ \\
\hline$V$ & $-\frac{\left(\ln \frac{I}{I_{0}}\right)}{L m_{s}}$ & 1 & 0.015 \\
$\frac{I}{I_{0}}$ & $-\frac{V\left(\frac{I}{I_{0}}\right)}{L m_{s}}$ & $\frac{1}{\ln \frac{I}{I_{0}}}$ & 0.023 \\
$L$ & $-\frac{V\left(\ln \frac{I}{I_{0}}\right)}{L^{2} m_{s}}$ & -1 & 0.010 \\
$m_{S}$ & $-\frac{V\left(\ln \frac{I}{I_{0}}\right)}{L m_{s}{ }^{2}}$ & -1 & 0.038 \\
\hline
\end{tabular}

The calculated uncertainty due to Type B uncertainty is $4.9 \%$. The uncertainty of the mass specific extinction measurements was greatly benefit from removing the influence of the smoke density.

The calculated $K_{m}$ values for smoke particles produced from burning ABS and UPVC are displayed in Figure 6. The calculated $K_{m}$ value for UPVC smoke particles is significantly lower than that of the ABS smoke particles, implying that more UPVC smoke loading to the TC (which has a finite volume) is required to achieve the same level of light obscuration as the ABS smoke particles. Significant differences in the $K_{m}$ between ABS and UPVC can be attributed to different morphology and composition of each of smoke particles.

From the experimental results, one can conclude that the concentration of UPVC smoke particles is considerably higher than that of the ABS smoke particles when each smoke particle fills a confined space, resulting in an identical level of light obscuration. These findings provide critical information for assessing and addressing the risk associated with polymer smoke hazards in a confined space, judging from the fact that smoke inhalation is the leading cause of death during fires. 


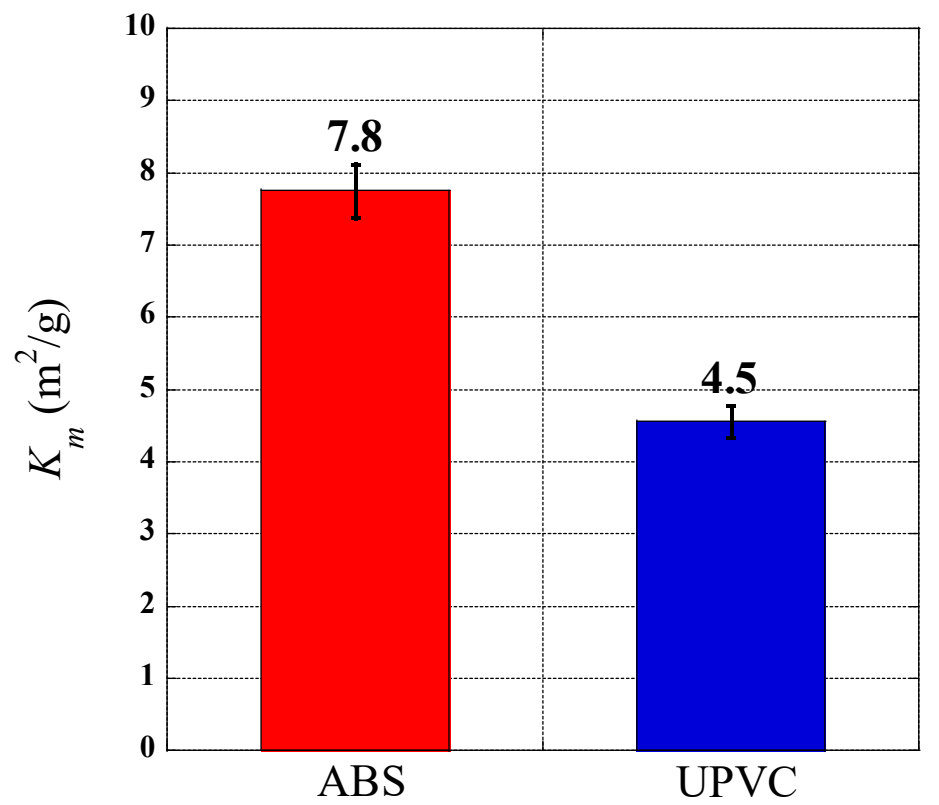

Figure 6. Comparisons of calculated mass-specific light-extinction constant for ABS and UPVC smoke particles.

Performance-based analysis has been used for fire safety design of numerous buildings. In this analysis, the assessment of the occupant safety in a confined space exposed to real fire conditions is related to the determination of the time when occupants are able to effectively evacuate before hazardous conditions sets in $[27,28]$. For example, a time parameter comparison between the available safe egress time (ASET) and the required safe egress time (RSET) is widely used amongst fire safety engineering practitioners [28]. The ASET/RSET method for fire safety assessment is a time-based approach that requires an accurate assessment of time dependent parameters associated with fire safety and human behaviors. Particularly, smoke behaviors and visibility, which are greatly influenced by smoke concentration and extinction coefficient (as identified in the present study), are one of important parameters for the ASET evaluation. Numerical simulation methods, such as computational fluid dynamics (CFD) have been adopted for the calculation of the ASET in the fire safety community. However, the availability of the ASET parameter for specific fire conditions are still lacking and the adequacy of CFD Model to evaluate the ASET parameter; in particular, the smoke optical density and concentration have not been well addressed in detail.

In the present study, a computational simulation was performed to quantitatively evaluate the effect of the $K_{m}$ and smoke concentration of the ABS and PVC smoke particles on smoke behaviors and visibility in the case of a fire in the space. The simulation was based on Fire Dynamics Simulator 6.7.1 (FDS 6.7.1), which is widely used to simulate fire phenomena based on large eddy simulation (LES). More information on the model and the governing Equations of FDS can be found elsewhere $[29,30]$. Figure 7 is a schematic diagram showing the IS0 9705 compartment and the location of the smoke detector applied in this study to simulate the behavior of smoke particles in a fire. The computational area inside the compartment was $8.54 \mathrm{~m} \times 2.13 \mathrm{~m} \times 2.13 \mathrm{~m}(\mathrm{xyz})$ and was calculated using a total of 2,566,400 meshes. In the center of the compartment, ABS and UPVC combustibles of the same size as used in the cone calorimetry experiment were set as the fire source, and the fire was numerically simulated by inputting the heat release rate derived from the results in Figure 3. 


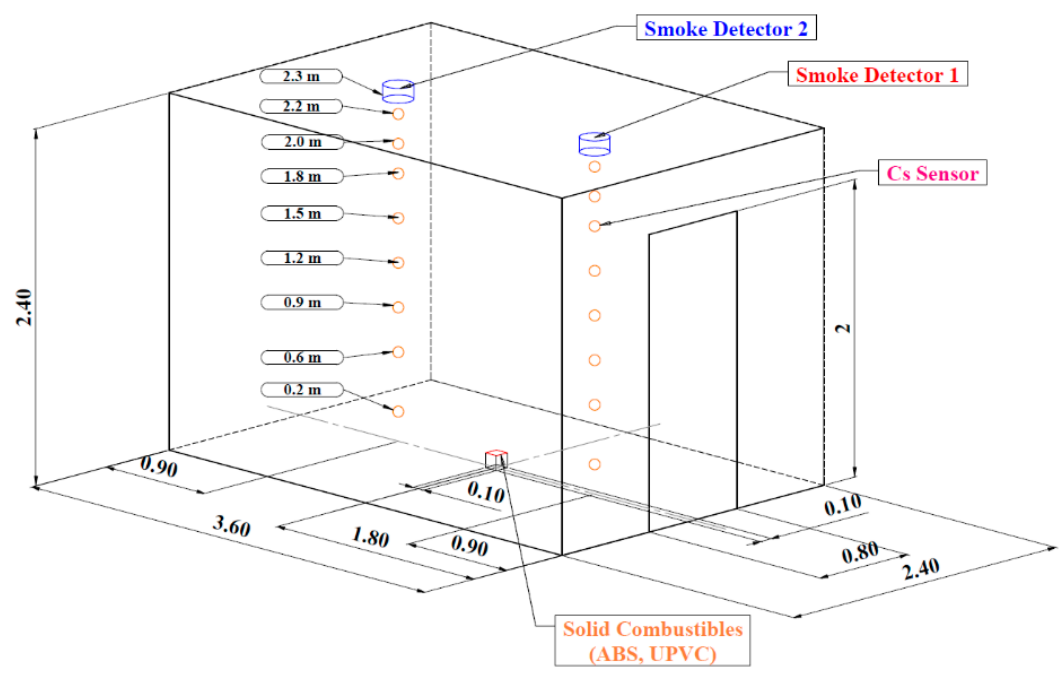

Figure 7. Schematics of ISO 9705 compartment and pre-selected locations of smoke detectors.

To quantitatively assess the influence of the smoke concentration and $K_{m}$ on smoke behaviors and its attendant effects on fire alarm time, the ABS and UPVC smoke yields were determined using Equation (7) and a data set obtained from simultaneous GSLE/cone calorimetry measurements:

$$
M_{S}=\frac{S E A}{K_{m}}, S E A=\frac{C_{s}, V_{d u c t}}{M L R}
$$

where $M_{S}$ is the smoke yield, $S E A$ the specific extinction area, $V_{d u c t}$ the volumetric flow rate measured in the duct exhaust, and MLR the mass loss rate of ABS and UPVC samples. The data set used to calculate the smoke yield is summarized in Table 2. As tabulated, the calculated smoke yield is 0.15 for the ABS sample and 0.11 for the UPVC sample, respectively.

Table 2. Summary of soot yield for ABS and UPVC smoke particles.

\begin{tabular}{ccc}
\hline Parameter & ABS & UPVC \\
\hline$V_{\text {duct }}(\mathrm{L} / \mathrm{s})$ & 24 & 24 \\
Time averaged $C_{s},(1 / \mathrm{m})$ & 10.83 & 3.25 \\
Time averaged $M L R(\mathrm{~g} / \mathrm{s})$ & 0.21 & 0.15 \\
$S E A\left(\mathrm{~m}^{2} / \mathrm{g}\right)$ & 1.23 & 0.52 \\
\hline$M_{S}$ (Soot yield) & 0.15 & 0.11 \\
\hline
\end{tabular}

To detect smoke particles signals caused by fire, FDS uses the calculated flow field information and the local concentration of smoke particles to determine the light obscuration per meter, $C_{s}$, in connection with the $K_{m}$ of the smoke particles, as shown in Equation. (3). Since $C_{s}$ in Equation (3) changes in a real fire with time, we can express the percent obscuration per meter $(O P M)(\% / \mathrm{m})$ as a function of time, as shown in Equation (8) [29]:

$$
O P M=\left\{1-\exp \left(C_{S}(t)\right)\right\} \times 100 \%
$$

In this study, when the OPM value inside the smoke detector reached $3.28 \% / \mathrm{m}$, the fire alarm signal was generated on the FDS simulations. The lag time of the smoke detector is affected by the internal shape of the detector and flow. Therefore, based on the empirical Equation (9), proposed by Cleary [31], the smoke detector's lag time (that can be generated by detector shape or internal flow) was taken into account [29]:

$$
t_{e}=\alpha_{e} u^{\beta_{e}} ; \quad t_{c}=\alpha_{c} u^{\beta_{c}}, \quad \Delta t=t_{e}+t_{c}
$$


where $t_{e}$ is the inflow time of the smoke particles into the detector, $t_{c}$ is the mixing time inside the detector of the smoke particles, $\Delta t$ is the response delay time of the detector, and $u$ is the moving velocity of the smoke particles. In addition, $\alpha$ and $\beta$ are constants determined empirically to consider the inflow and mixing of smoke particles, respectively. $\alpha_{c}$ and $\beta_{c}$ were set to 0.8 and -0.9 , respectively, for the calculation [32].

The results of light obscuration calculated with each of $K_{m}$ and $M_{s}$ for ABS and UPVC smoke particles are displayed in Figure 8. As shown in Figure 8, most of the smoke particles are located in the upper part of the compartment owing to buoyancy. However, the calculated results indicate that smoke particles produced from burning UPVC and ABS exhibit distinct smoke behaviors. ABS smoke particles fill the compartment quickly and the light obscuration effect is visibly large compared to UPVC smoke particles. As time progresses, the ABS smoke particles result in greater increases in the $C_{S}$ compared to UPVC smoke particles. Moreover, the thickness of the smoke layer produced from burning ABS below the ceiling becomes much thicker than in case of UPVC. This is mainly attributed to the fact that ABS has a relatively high smoke yield compared to UPVC and releases more heat as manifested in Figure 3. The heat released from burning ABS, which is relatively large compared to PVC, causes a large flow inside the compartment due to the increased buoyancy. At the same time, the large amount of smoke particles for ABS rapidly moves to the floor along with buoyancy-induced flow, increasing the thickness of smoke layer. This belief is clearly supported by Figure 9 that displays the calculated flow field at $500 \mathrm{~s}$ after ignition. As shown in the Figure 9, burning ABS creates a stronger circulating air flow inside the compartment compared to PVC.

In addition to the influence of the smoke yield coupled with buoyancy flow, another factor that can affect smoke behaviors is the light extinction coefficient, as described above. In order to better evaluate the light obscuration caused by smoke particles, it is important to choose an appropriate $K_{m}$, which varies with the type of fuel. To quantitatively evaluate the effect of the $K_{m}$ value on light obscuration, we performed another FDS simulation, where the $K_{m}$ for both ABS and UPVC smoke particles was fixed to the default value of $8.7 \mathrm{~m}^{2} / \mathrm{g}$ set in FDS, while the $M_{s}$ for each of polymers remained unchanged. Numerical results displayed in Figure 9 clearly highlight the effect of $K_{m}$ on smoke behaviors. It can be seen that the thickness of smoke layer and $C_{s}$ calculated for ABS smoke particles are almost unchanged since the selected $K_{m}$ value of $8.7 \mathrm{~m}^{2} / \mathrm{g}$ is close to the actual measured value of $7.8 \mathrm{~m}^{2} / \mathrm{g}$ within a range of $K_{m}$ uncertainty. On the other hand (Figure 10), in case of PVC smoke particles, the $K_{m}$ value set to $8.7 \mathrm{~m}^{2} / \mathrm{g}$ which is approximately a factor of 2 higher than the actual measured value $\left(=4.5 \mathrm{~m}^{2} / \mathrm{g}\right)$ results in gradual increases in the calculated $C_{s}$.

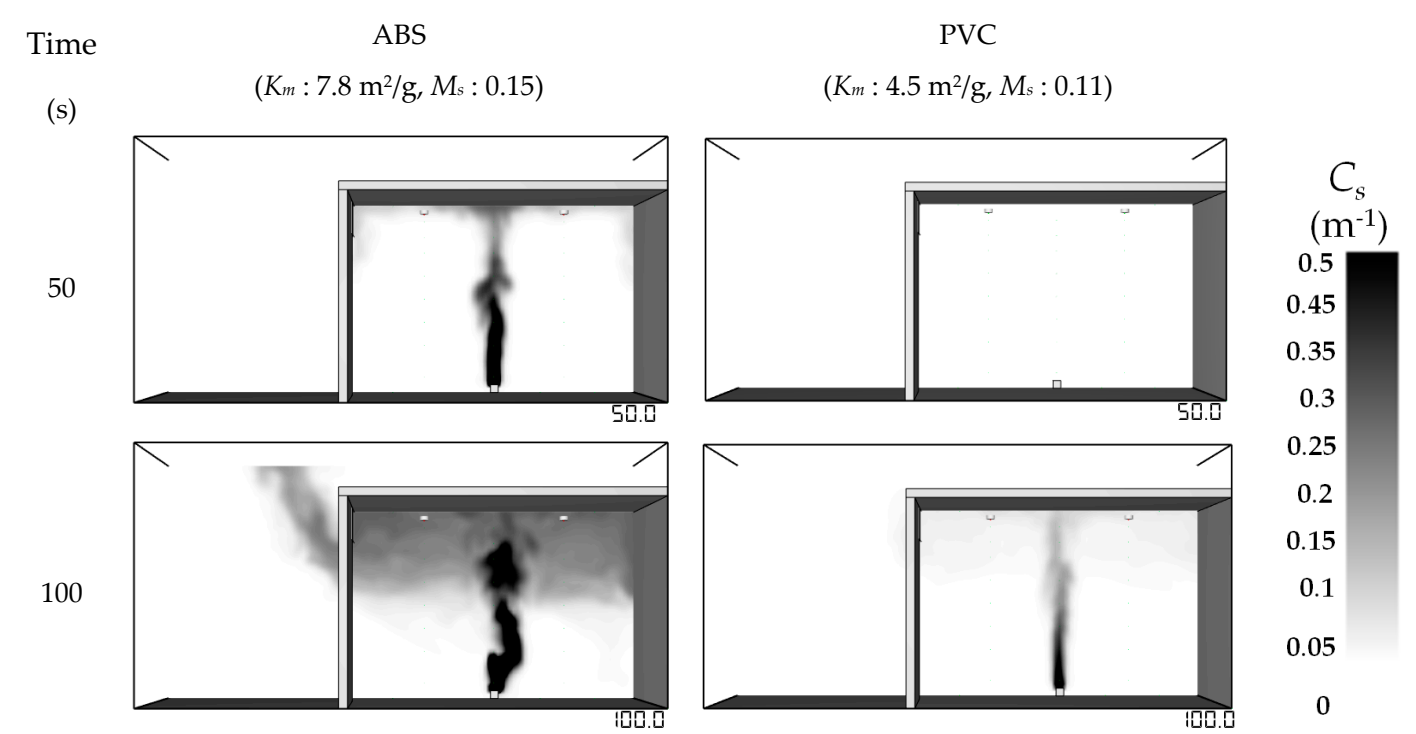

Figure 8. Cont. 

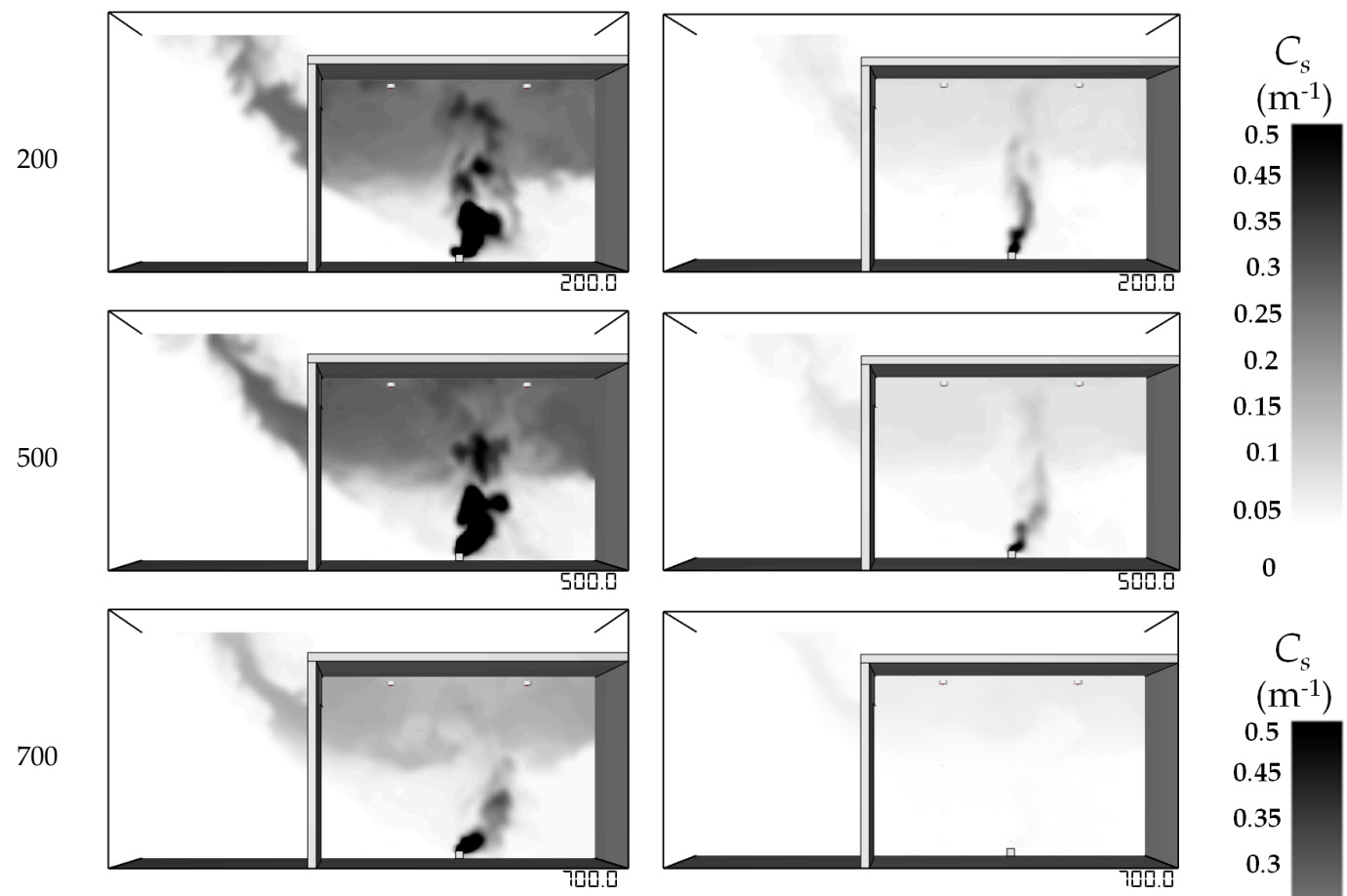

0.25
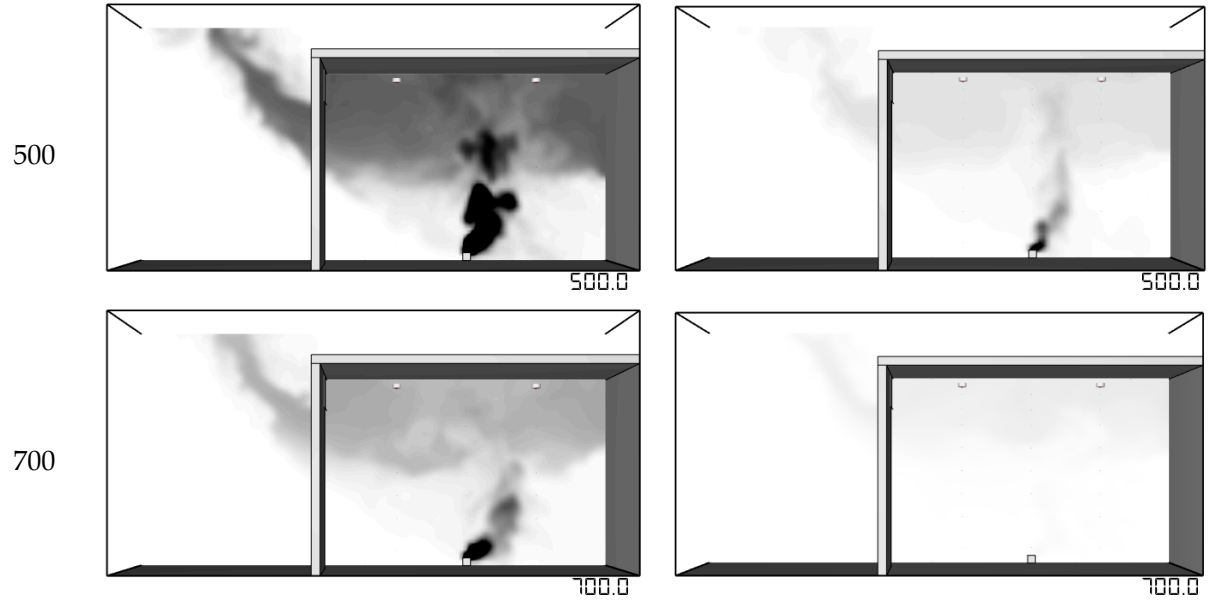

$C_{S}$ $\left(\mathrm{m}^{-1}\right)$ 0.5
0.45
0.35
0.3
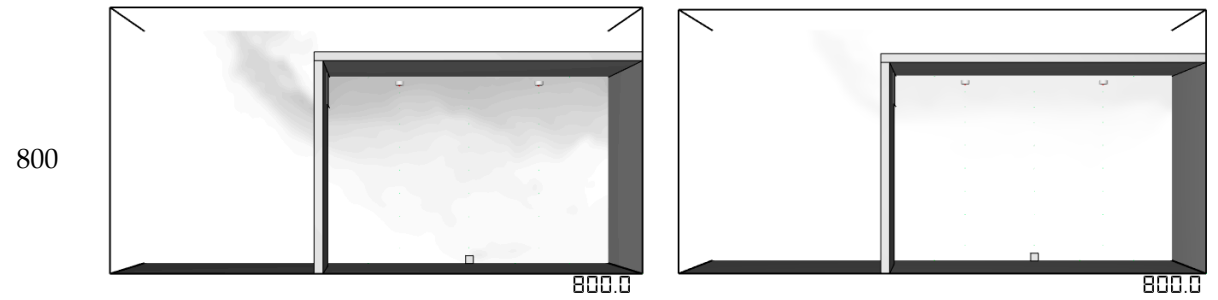

0.25

0.2

0.15

0.1

0.05

0

Figure 8. Calculated $C_{s}$ with the measured $K_{m}$ and $M_{s}$ for each of the polymers as a function of time.

Time

(s)

$$
\left(K_{m}: 7.8 \mathrm{~m}^{2} / \mathrm{g}, M_{s}: 0.15\right)
$$

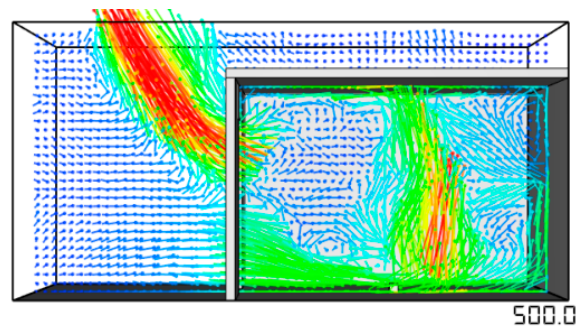

PVC

$\left(K_{m}: 4.5 \mathrm{~m}^{2} / \mathrm{g}, M_{s}: 0.11\right)$

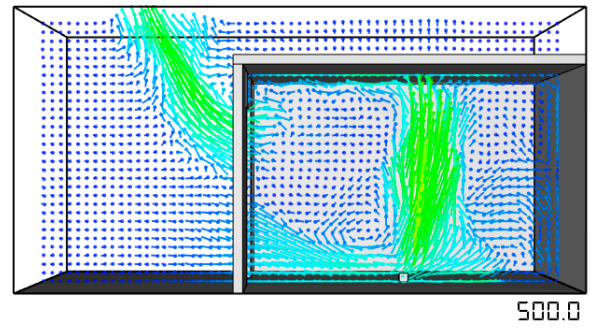

Figure 9. Calculated flow field at $500 \mathrm{~s}$ after ignition. 
Time

(s)
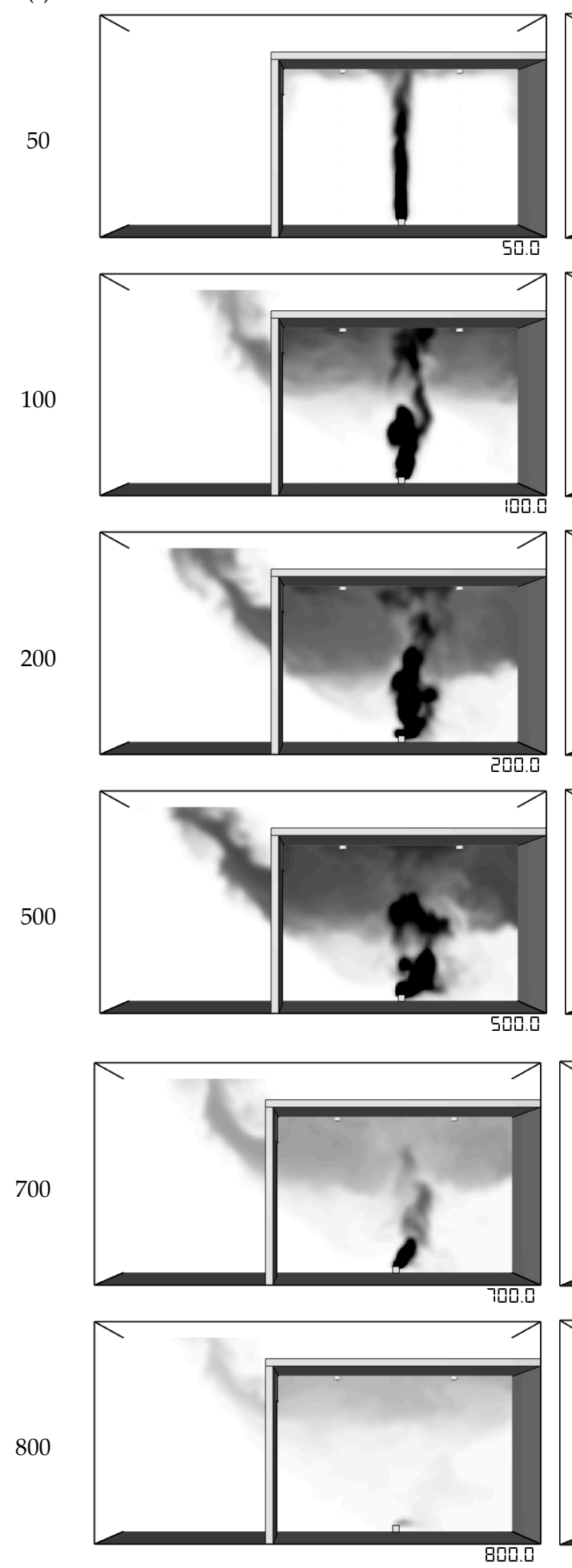

PVC

$\left(K_{m}: 8.7 \mathrm{~m}^{2} / \mathrm{g}, M_{s}: 0.11\right)$
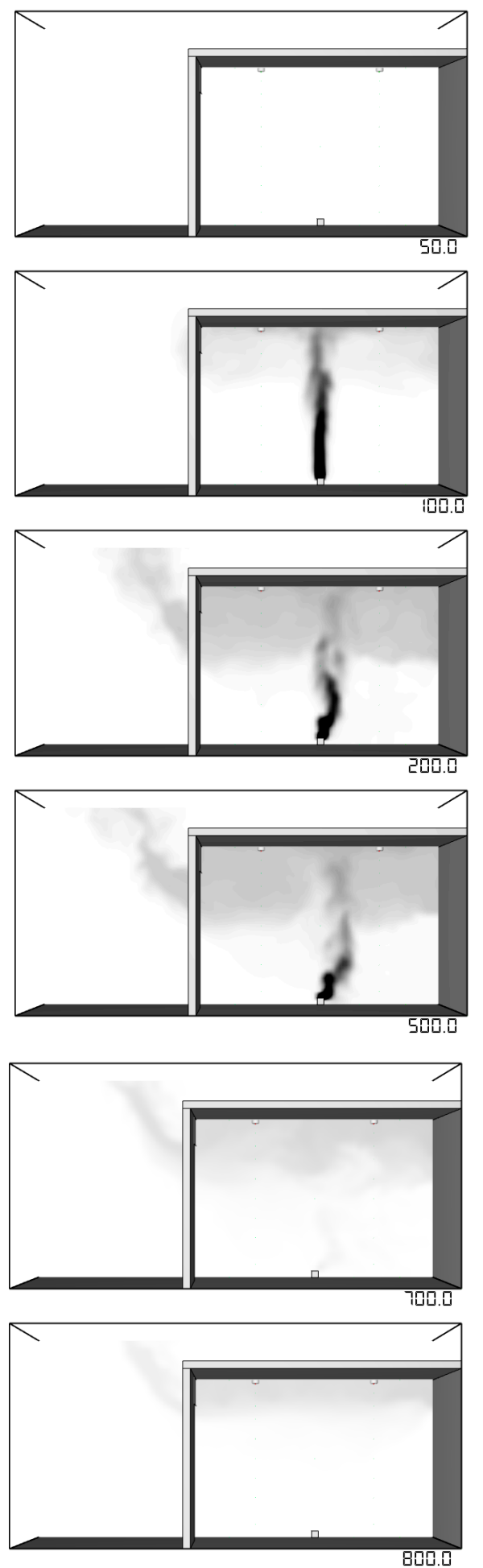

0.25

0.2

0.15

0.1

0.05

0

$\mathrm{C}_{\mathrm{s}}$

$\left(\mathrm{m}^{-1}\right)$

0.5
0.45

0.35

0.3

0.25

0.2

0.15

0.1

0.05

0

$C_{s}$ $\left(\mathrm{m}^{-1}\right)$

0.5

0.45

0.35

0.3

25

15

$C_{s}$

$\left(\mathrm{m}^{-1}\right)$

0.5

0.45

0.35

0.3

0.25

0.2

0.15

0.1

0.05

0

Figure 10. Calculated $C_{s}$ with the $K_{m}$ of $8.7 \mathrm{~m}^{2} / \mathrm{g}$ for both polymers as a function of time.

To further elucidate the impact of $M_{s}$ and $K_{m}$ of smoke particles on smoke behaviors, the initial alarm time (fire detection time) of the smoke detector predicted on the FDS based on the OPM value calculated by Equation (5) is shown in Figure 11. As shown in the figure, when the UPVC is combusted inside the same compartment, it takes much longer to detect a fire with a smoke detector than in the 
case of ABS. This means that in the same space, a fire caused by UPVC may result in the fire alarm being triggered much later than a fire caused by ABS, leading to more casualties because of the delay in evacuation. In addition, careful precautions are required to estimate the fire detection time on the FDS when dealing with UPVC that has much lower value of $K_{m}, 4.5 \mathrm{~m}^{2} / \mathrm{g}$ than other hydrocarbon fuels reported in the literature $[6,8,11,23]$. For example, the use of $8.7 \mathrm{~m}^{2} / \mathrm{g}$ that is conventionally used as the mass specific extinction coefficient in the fire science community can lead to a significant underestimation of the fire detection time, as shown in Figure 11.

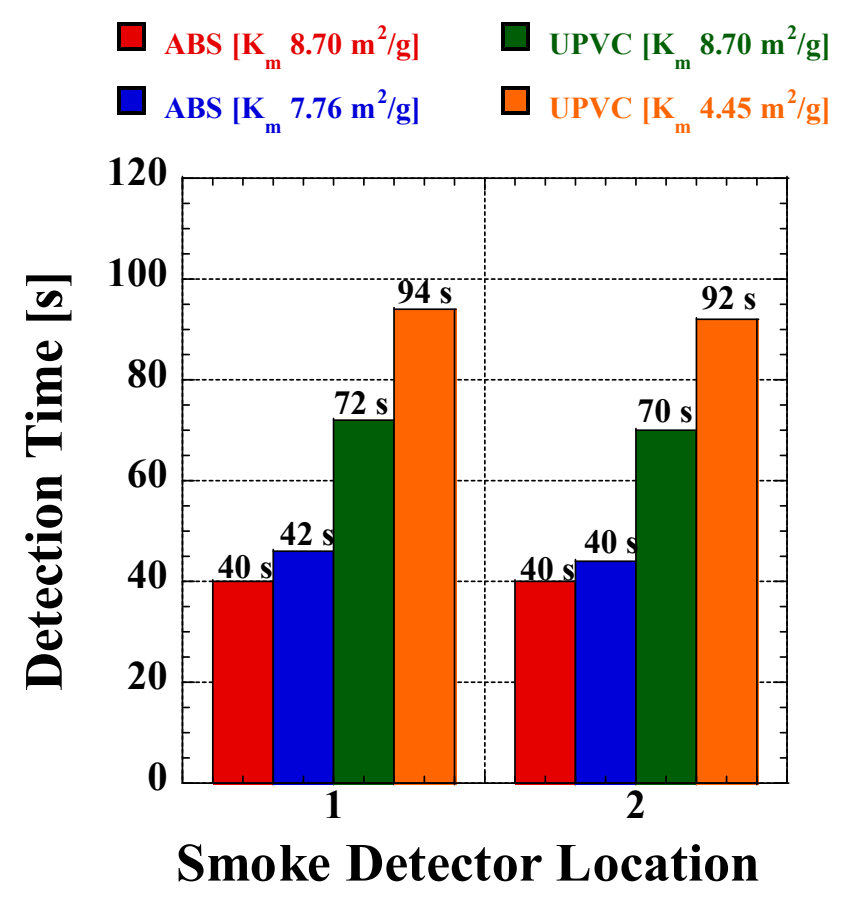

Figure 11. Comparison of alarm time calculated for ABS and UPVC combustion cases.

\section{Conclusions}

The optical properties of smoke particles generated from burning polymeric materials were experimentally investigated in the present study. ABS and UPVC, which have been widely used in home and building applications, were selected as representative smoke-emitting polymeric materials and burned at atmospheric pressure to generate smoke particles. The light obscuration behaviors of the ABS and UPVC smoke particles obtained from the cone calorimetry experiments and simultaneous GSLE measurements and their attendant impacts on smoke behavior in a confined space can be summarized as:

(1) The heat release rate measured from burning the UPVC samples was much lower than that measured from burning ABS samples. This caused a low rate of smoke production for the UPVC samples during combustion, eventually resulting in substantial reductions in the light obscuration.

(2) UPVC smoke particles were also found to represent a lower efficiency of light absorption and scattering per unit concentration, resulting in a $41.3 \%$ reduction in the mass specific extinction coefficient compared to ABS smoke particles.

(3) Using the mass specific extinction coefficients obtained from the simultaneous GSLE measurements, numerical analysis on the smoke behavior was performed using FDS. The analysis results showed that in the case of UPVC combustion inside the same compartment, with its relatively mass specific extinction coefficient, it takes much longer than in the case of ABS to detect a fire with a smoke detector These findings provide an important foundational understanding of the light obscuration characteristics of smoke particles generated from polymer combustion, and their attendant impacts on fire evacuation, which have not been investigated previously. 
Author Contributions: S.-H.P. provided the main idea of the study; T.-K.H. designed and performed the experiments; B.-S.R. analyzed the experiments data; T.-K.H. wrote the original draft; S.-H.P. reviewed and edited the draft. All authors have read and agreed to the published version of the manuscript.

Funding: This research was supported by the Field-oriented Support of Fire Fighting Technology Research and Development Project of the National Fire Agency (MPSS-Fire Safety-2015-66) and Korea Electric Power Corporation (Grant Number: R18XA06-64).

Conflicts of Interest: The authors declare no conflict of interest.

\section{References}

1. Shaddix, C.R.; Williams, T.C. Soot: Giver and taker of light. Am. Sci. 2007, 95, 232-239. [CrossRef]

2. Modest, M.F. Radiative Heat Transfer, 2nd ed.; McGraw-Hill: New York, NY, USA, 1993.

3. Yi, X.; Lei, C.; Deng, J.; Ma, L.; Fan, J.; Liu, Y.; Bai, L.; Shu, C.M. Numerical simulation of fire smoke spread in a super high-rise building for different fire scenarios. Adv. Civ. Eng. 2019, 2019, 1-11. [CrossRef]

4. Tawiah, B.; Yu, B.; Wei, R.; Yuen, R.K.; Chen, W.; Xin, J.H.; Fei, B. Simultaneous fire safety enhancement and mechanical reinforcement of poly(lactic acid) biocomposites with hexaphenyl(nitrilotris(ethane-2, 1-diyl))tris(phosphoramidate). J. Hazard. Mater. 2019, 380, 120856. [CrossRef] [PubMed]

5. Liang, Q.; Xu, H.; Huang, Y.; Li, Y. Numerical studies on the smoke control parameters of water mist screens with transverse ventilation system in tunnel fires. In Asia-Oceania Symposium on Fire Science and Technology; Springer: Singapore, 2018; pp. 1061-1074.

6. Williams, T.C.; Shaddix, C.R.; Jensen, K.A.; Suo-Anttila, J.M. Measurement of the dimensionless extinction coefficient of soot within laminar diffusion flames. Int. J. Heat Mass Transf. 2007, 50, 1616-1630. [CrossRef]

7. Shaddix, C.R.; Palotás, Á.B.; Megaridis, C.M.; Choi, M.Y.; Yang, N.Y.C. Soot graphitic order in laminar diffusion flames and a large-scale JP-8 pool fire. Int. J. Heat Mass Transf. 2005, 48, 3604-3614. [CrossRef]

8. Jensen, K.A.; Suo-Anttila, J.M.; Blevings, L.G. Measurement of soot morphology, chemistry, and optical properties in the visible and near-infrared spectrum in the flame zone and overfire region of large JP-8 pool fires. Combust. Sci. Technol. 2007, 179, 2453-2487. [CrossRef]

9. Kocifaj, M.; Videen, G. Optical behavior of composite carbonaceous aerosols: DDA and EMT approaches. J. Quant. Spectrosc. Radiat. Transf. 2008, 109, 1404-1416. [CrossRef]

10. Kocifaj, M.; Gangl, M.; Kundracík, F.; Horvath, H.; Videen, G. Simulation of the optical properties of single composite aerosols. J. Aerosol Sci. 2006, 37, 1683-1695. [CrossRef]

11. Choi, S.C.; Park, S.H.; Choi, M.Y. Measurements of the dimensionless light extinction constant for diesel and biodiesel soot in the visible and near-infrared wavelengths. J. Chem. Eng. Jpn. 2016, 49, 563-572. [CrossRef]

12. Dalzell, W.H.; Sarofim, A.F. Optical constants of soot and their application to heat-flux calculations. J. Heat Transf. 1969, 91, 100-104. [CrossRef]

13. Smyth, K.C.; Shaddix, C.R. The elusive history of $\mathrm{m} \sim=1.57-0.56 \mathrm{i}$ for the refractive index of soot. Combust. Flame 1996, 107, 314-320. [CrossRef]

14. Shemwell, B.E.; Levendis, Y.A. Particulates generated from combustion of polymers (plastics). J. Air Waste Manag. Assoc. 2000, 50, 94-102. [CrossRef] [PubMed]

15. Cheng, J.J.; Sun, S.H. Investigation on the fire hazard of hybrid polymer materials based on the test of smoke toxicity. J. Therm. Anal. Calorim. 2019, 135, 2347-2357. [CrossRef]

16. Salasinska, K.; Barczewski, M.; Borucka, M.; Górny, R.L.; Kozikowski, P.; Celiński, M.; Gajek, A. Thermal stability, fire and smoke behaviour of epoxy composites modified with plant waste fillers. Polymers 2019, 11, 1234. [CrossRef]

17. Lyon, R.E.; Janssens, M.L. Polymer Flammability; Report No.: DOT/FAA/AR-05/14; Federal Aviation Administration: Springfield, VA, USA, 2005.

18. Guyot, A.; Bert, M.; Michel, A. Smoke reduction from polyvinyl chloride (PVC). Fire Saf. J. 1983, 5, $287-297$. [CrossRef]

19. Wang, Z.; Huang, P.; Fan, W.C.; Wang, Q. Measurements on the fire behaviour of PVC Sheets using the cone calorimeter. Fire Saf. Sci. 1988, 3, 221-228.

20. Laoutid, F.; Duriez, V.; Brison, L.; Aouadi, S.; Vahabi, H.; Dubois, P. Synergistic flame-retardant effect between lignin and magnesium hydroxide in poly(ethylene-co-vinyl acetate). Flame Retard. Therm. Stab. Mater. 2019, 2, 9-18. [CrossRef] 
21. Günther, M.; Lorenzetti, A.; Schartel, B. Fire phenomena of rigid polyurethane foams. Polymers 2018, 10, 1166. [CrossRef]

22. Twilley, W.H.; Babrauskas, V. User's Guide for the Cone Calorimeter; NBS Special Publication 745; Government Printing Office: Washington, DC, USA, 1998.

23. Mulholland, G.W.; Croarkin, C. Specific extinction coefficient of flame generated smoke. Fire Mater. 2000, 24, 227-230. [CrossRef]

24. Wang, X.; Zhou, H.; Arnott, W.P.; Meyer, M.E.; Taylor, S.; Firouzkouhi, H.; Moosmüller, H.; Chow, J.C.; Watson, J.G. Characterization of smoke for spacecraft fire safety. J. Aerosol Sci. 2019, 136, 36-47. [CrossRef]

25. Choi, M.Y.; Mulholland, G.W.; Hamins, A.; Kashiwagi, T. Comparisons of the soot volume fraction using gravimetric and light extinction techniques. Combust. Flame 1995, 102, 161-169. [CrossRef]

26. Swinehart, D.F. The beer-lambert law. J. Chem. Educ. 1962, 39, 333-335. [CrossRef]

27. Poon, S.L. A dynamic approach to ASETRSET assessment in performance based design. Procedia Eng. 2014, 71, 173-181. [CrossRef]

28. Corches, A.-M.; Ulriksen, L.; Jomaas, G. FDS modeling of the sensitivity of the smoke potential values used in fire safety strategies. In Proceedings of the 10th International Conference on Performance Based Codes and Fire Safety Design Methods, Gold Coast, Australia, 10-12 November 2014.

29. McGrattan, K.; Hostikka, S.; McDermott, R.; Floyd, J.; Weinschenk, C.; Overholt, K. Fire Dynamic Simulator User's Guide; NIST Special Publication: Gaithersburg, MD, USA, 2017.

30. Robbins, A.P.; Wade, C.A. Soot Yield Values for Modelling Purposes-Residential Occupancies; BRANZ Study Report 185; BRANZ Ltd.: Porirua, New Zealand, 2007.

31. Thomas, G.C.; Artur, A.C.; William, L.G.; Michael, D.A. Particulate entry lag in spot-type smoke detectors. Fire Saf. Sci. 1999, 6, 779-790.

32. Roby, R.J.; Olenick, S.J.; Zhang, W.; Carpenter, D.J.; Klassen, M.S.; Torero, J.L. A Smoke Detector Algorithm for Large Eddy Simulation Modeling; NIST GCR 07-911; National Institutes of Standards and Technology: Gaithersburg, MD, USA, 2007.

(C) 2020 by the authors. Licensee MDPI, Basel, Switzerland. This article is an open access article distributed under the terms and conditions of the Creative Commons Attribution (CC BY) license (http://creativecommons.org/licenses/by/4.0/). 